\title{
Historical Context of Behavioral Economics
}

\author{
Dr. Tansif ur Rehman \\ Department of Criminology, University of Karachi, Pakistan
}

Corresponding author: Dr. Tansif ur Rehman, Department of Criminology, University of Karachi, Pakistan. E-mail: Tansif@live.com

Received Date: February 16, 2021; Accepted Date: March 26, 2021; Published Date; April $03,2021$.

Citation: Tansif ur Rehman, Historical Context of Behavioral Economics, J. Psychology and Mental Health Care. 6(1); Doi:10.31579/2637-8892/110.

Copyright: (C) 2021 Tansif ur Rehman, This is an open-access article distributed under the terms of the Creative Commons Attribution License, which permits unrestricted use, distribution, and reproduction in any medium, provided the original author and source are credited.

\begin{abstract}
:
Behavioral economics, at broad level, superimpose many areas including Psychology and Economics. Behavioral economics by all means enhances the explanatory power of Economics as it provides it with a firm and more rational psychological basis. During the previous 20 years, many studies have explored different aspects of behavioral economics leading to introduction of the respective principles that pertain to human behavior. This article intends to provide an introduction to behavioral economics in its historical context. It also investigates the gaps that lie in the broad spectrum of behavioral economics.
\end{abstract}

Keywords: behavioral economics; historical context; psychology; qualitative

\section{Introduction}

Behavioral economics is not as apparently defined a field such as other fields of social sciences, however, in the labs the psychological experimentation is its focused methodology, as it has progressively more applicability in the natural environment. The standard estimations of traditional economists regarding the nature of humans have been under intensive assessment by the contemporary economists who follow the concept of individuals' psychology of making decisions. The traditional economists are influenced by the concept of homo-economics, which can be explained as the rational, utility or benefit maximizing, and cost minimizing individuals with relatively stable preferences. If it is intended to cause a transformation in behavior, then the only way is to avoid manipulated and wrong information or by offering some benefits.

Conversely, behavioral economics can be explained as, the context which also has a great impact on the decision making. Human behavior differs depending on the circumstances, location, time, influences of society, emotional judgments, thoughts based on prejudice, and simultaneously how they make their choices. The consequences of involuntary and organize processes leads to form one choice rather than to follow the basic model that the majority believes.

In the last decade the theories regarding 'Dual-process' have gained much momentum as various researches have been conducted in this sphere (Evans, 2010; Evans \& Frankish, 2009; Lieberman, 2007; Reyna, 2004; Stanovich \& West, 2000). While, there also has been much criticism, for e.g., Keren and Schul (2009), Osman (2004), and Kruglanski and Gigerenzer (2011). In reality, the drawing of respective developmental predictions from these theories is a complex phenomenon altogether; as, overly simplified predictions emerging from these models may even lead to its rejection in the first place, i.e., premature rejection of the dual process approach.

According to Stanovich and West (2000), the two systems of thought that have been differentiated with its individual competences by the psychologists; can be named as Systems 1 and 2. Higgins (1996) believes that the System 1 can be explained in term of implicit, that is, embedded thoughts, which are involuntary and relational, thought process based on experiences, non-deliberative procedures and influential links. Simultaneously, the implicit system is applicable to the evaluation of evidences to make decisions that are the reflection of the opinion based on perception that can be easily obtained (Kahneman \& Frederick, 2002).

While, the System 2 is explicit, that is, to scrutinize and analyze cognitive processes and expressed unconcealed behavior. System 2 is comparatively considered to be more influential than System 1 as it is, under control, intentional, purposeful, and based on analysis. In order to find how System 2 can be applied to the routine life, it can be explained in terms of planning a strategy; on the other hand, the System 1 can be understood by the example of the autopilot that travel on a daily basis to work. Many facets of behavioral economics are covered by these two respective systems. System 1 plays a very important role in decision making, particularly when there is a need to make judgments under the circumstances of ambiguity, limitation of time, and thought processes.

Kahneman and Frederick (2002) are of the view that the constraints related to System 2 pertains to the idea of bounded rationality, the limitations faced during the information processing among human is to reach a certain decision beside the limitations in System 1, that is,

1.Knowledge (information) 2.Available time 3.Computational capacities

(Gigerenzer, Hell, \& Blank, 1988; Goldstein \& Weber, 1995; Simon, 1955).

In 'typical' performance situations the respective interpretation of the task to some extent is determined by the participant, i.e. these sort of situations are unconstrained in their very nature. These are in fact the reflective mind measures as they assess in epistemic regulation as well as goal prioritization.

Measures of thinking dispositions along with the cognitive style facilitates the very process of assessing the reflective level of cognition. Cacioppo et al. (1996), Kruglanski and Webster (1996), Stanovich and West (2000), 
Strathman, Gleicher, Boninger, and Scott Edwards (1994), and Sternberg (2003) have investigated some of the various examples of thinking dispositions like, consideration of future consequences, dogmatism, need for cognition, need for closure, open-minded thinking, superstitious thinking, etc.

On the contrary, when the task interpretation is determined externally it is referred as being an 'optimal' performance, thus the individual involved is instructed to maximize the respective performance. This type of performance measures actually examines the very questions of the efficiency of pursuing a specific goal. All cognitive aptitude or intelligence tests are optimal performance assessments, as they capture the efficiency of processing of individuals with respect to the algorithmic mind framework.

Illogicality does not associate with bounded rationality. Heuristic reasoning is the mental processing that involves the shortest way to reach a certain decision, which is based on the reasoning in terms of their alteration and management of the arrangement of the surrounding environment (Gigerenzer et al., 1988). These are considered to be the most favorable aspect within the thought processing ability of humans. In this research study, different factors of bounded rationality are intended to be studied, that include internal forces (cognition), physical environment, and social aspects based on reality which are the contrary outlooks of the rational choice concept cited by the traditional economists.

By no means, behavioral economics is a clearly delineated field of study like most of the studies of social sciences. How- ever, psychological experimentation is its methodological focus. Previously, it was aimed at focusing within the parameters of the lab, but in the contemporary era it is also being tested in the natural environment, i.e. the field settings. Behavioral economics surely overlaps in various fields of social sciences, i.e. economics, psychological domains like cognitive psychology, ecological psychology, evolutionary psychology, social psychology, sociology, and even anthropology to an extent. A number of diversified phenomena pertinent to behavioral economics have been researched by scholars from a variety of different fields over the last couple of decades, and they also have been successful in deriving a series of respective behavioral principles.

The application of behavioral economics can be seen within the decision makings related to market as well as the individual preferences and choices can be characterized in terms of behavior leading to vigorous usage of conformity as well as on the transformation of behavior related to various aspects. Nowadays, many publications within the area of behavioral economics and Psychology contributed to increase the knowhow of this concept that have captured the consideration of the respective systems pertaining the economic activities.

\section{Side headings/Sub headings}

What behavioral economics really does; Evaluating behavioral economics; The historical context of behavioral economics; Psychology: an assumption or a conclusion?; Final thoughts

\section{Discussion \& Conclusion}

The explanatory power of Economics is increased by behavioral economics as it provides it with a more realistic, psycho- logical foundation by encompassing various pertinent aspects adhering to it. Behavioral economics has a great impact on the decision making of individuals, as human behavior differs depending on the circumstances, time, location, emotional judgments as well as societal influences. Behavioral economics central point lies in the aspect that the psychological (behavioral) base of economic analysis will add up to the overall contextual body of Economics respectively.

Behavioral economics possess the very potential to be a helpmate of rational choice theory. Utility can be enhanced in some of the contexts where careful framing is used. For those respective contexts, the model of rational choice must bend to accommodate behavioral insights in all dimensions, i.e., by providing them a prescriptive weight. Undoubtedly, rational choice theory will be able to make even better predictions and justified prescriptions, as if it really can embrace as well as reflect the significant lessons that emerge from the context of behavioral economics.

\section{Conflict of Interest}

The author declares that there is no conflict of interest to this article.

\section{References}

1. Evans, J. St. B. T. (2010). Thinking twice: Two minds in one brain. Oxford: Oxford University Press.

2. Evans, J. St. B. T., \& Frankish, K. (Eds. ). (2009). Two minds: Dual processes and beyond. Oxford: Oxford University Press.

3. Lieberman, M. D. (2007). Social cognitive neuroscience: A review of core processes.

4. Annual Review of Psychology, 58, 259-289.

5. Reyna, V.F. (2004). How people make decisions that involve risk: A dual-processes approach. Current Directions in Psychological Science, 13, 60-66.

6. Stanovich, K. E., \& West, R. F. (2000). Individual differences in reasoning: Implications for the rationality debate? Behavioral and Brain Sciences, 23, 645-726.

7. Keren, G., \& Schul, Y. (2009). Two is not always better than one: A critical evaluation of two-system theories. Perspectives on Psychological Science, 4, 533-550.

8. Osman, M. (2004). An evaluation of dual-process theories of reasoning. Psychonomic Bulletin \& Review, 11, 988-1010.

9. Kruglanski, A. W., \& Gigerenzer, G. (2011). Intuitive and deliberate judgments are based on common principles. Psychological Review, 118, 97-109.

10. Stanovich, K. E., \& West, R. F. (2000). Individual differences in reasoning: Implications for the rationality debate? Behavioral and Brain Sciences, 23, 645-726.

11. Higgins, E. T. (1996). Knowledge activation: Accessibility, applicability, and salience. In E. T. Higgins, \& A. W. Kruglanski (Eds.), Social psychology: Handbook of basic principles (pp. 133168). New York: The Guilford Press.

12. Kahneman, D. J., \& Frederick, S. (2002). Representativeness revisited: Attribution substitution in intuitive judgment. In T. Gilovich, D. Griffin, \& D. Kahneman (Eds.), Heuristics of intuitive judgment: Extensions and applications. New York: Cambridge University Press.

13. Gigerenzer, G., Hell, W., \& Blank, H. (1988). Presentation and content: The use of base rates as a continuous variable. Journal of Experimental Psychology, 14(3), 513-525. Goldstein.

14. W. M., \& Weber, E. U. (1995). Content and its discontents: The use of knowledge in decision making. In J. R. Busemeyer, R. Hastie, \& D. L. Medin (Eds.). In Decision making from a cognitive perspective. The psychology of learning and motivation: Vol. 32 (pp. 83-136). New York, NY: Academic Press.

15. Simon, H. A. (1955). A behavioral model of rational choice. The Quarterly Journal of Economics, 69, 99-118.

16. Cacioppo, J. T., Petty, R. E., Feinstein, J., \& Jarvis, W. (1996). Dispositional differences in cognitive motivation: The life and times of individuals varying in need for cognition. Psychological Bulletin, 119, 197-253.

17. Kruglanski, A. W., \& Webster, D. M. (1996). Motivated closing the mind: 'Seizing' and 'freezing'. Psychological Review, 103, 263-283.

18. Stanovich, K. E., \& West, R. F. (2000). Individual differences in reasoning: Implications for the rationality debate? Behavioral and 
Brain Sciences, 23, 645-726.

19. Strathman, A., Gleicher, F., Boninger, D. S., \& Scott Edwards, C. (1994). The consideration of future consequences: Weighing immediate and distant outcomes of behavior. Journal of Personality and Social Psychology, 66, 742-752.

20. Sternberg, R. J. (2003). Wisdom, intelligence, and creativity synthesized. Cambridge: Cambridge University Press.

21. Gigerenzer, G., Hell, W., \& Blank, H. (1988). Presentation and content: The use of base rates as a continuous variable. Journal of Experimental Psychology, 14(3), 513-525. 